\title{
CYP1B1 G199T Polymorphism Affects Prognosis of NSCLC Patients with the Potential to Be an Indicator and Target for Precise Drug Intervention
}

\author{
Fengzhou Li, ${ }^{1,2}$ Shaofeng Zhang, ${ }^{3}$ Qi Zhang, ${ }^{4}$ Jinxiu Li, ${ }^{2}$ Shilei Zhao,, ${ }^{1,2}$ and Chundong Gu ${ }^{1,2}$ \\ ${ }^{1}$ Department of Thoracic Surgery, The First Affiliated Hospital of Dalian Medical University, Dalian, Liaoning 116011, China \\ ${ }^{2}$ Lung Cancer Diagnosis and Treatment Center, Dalian, Liaoning 116011, China \\ ${ }^{3}$ Department of Thoracic Surgery, Xingtai People’s Hospital, Xingtai, Hebei 054031, China \\ ${ }^{4}$ China National Research Institute of Food \& Fermentation Industries, Beijing 100015, China
}

Correspondence should be addressed to Jinxiu Li; lijinxiu@dmu.edu.cn and Chundong Gu; guchundong@dmu.edu.cn

Received 31 December 2016; Accepted 22 January 2017; Published 9 March 2017

Academic Editor: Alexander N. Orekhov

Copyright (C) 2017 Fengzhou Li et al. This is an open access article distributed under the Creative Commons Attribution License, which permits unrestricted use, distribution, and reproduction in any medium, provided the original work is properly cited.

\begin{abstract}
CYP1B1 gene single nucleotide polymorphisms G119T, C432G, and A453G were tested among 164 NSCLC patients treated by VideoAssisted Thoracoscopic Surgery. After a follow-up period of 5 years, it was found that CYP1B1 G119T mutant genotypes were related to a higher risk of tumor recurrence and death after surgical resection. However, C432G and A453G genotypes had no influence on long-term prognosis of the study cohort. Thus, G199T alleles are supposed to be an auxiliary predictor for prognosis of NSCLC patients and a potential target for precise drug intervention, as well as a candidate for further anticancer drug research.
\end{abstract}

\section{Introduction}

Lung cancer is the most common malignancy and cause of cancer death in China, as was claimed in the latest epidemiological report published by the National Cancer Center in 2015 [1]. Non-small cell lung cancer (NSCLC) accounts for approximately $85 \%$ of all lung cancers, and surgical operation is the major treatment method [2]. Along with medicine unceasing progress, the diagnosis and treatment methods of NSCLC were improved dramatically. However, the 5-year survival rate of NSCLC patients remains as low as 15 16\% [3, 4]. Drug adjuvant therapies such as chemotherapy, molecular targeting treatment, or herbal therapies [5] are often required in order to improve the overall survival of those patients with high recurrence risks. Accurate and efficient predictors for NSCLC postoperative prognosis as well as potential targets for precise drug interventions are still needed [6].

Cytochrome P450 (CYP450), a superfamily of enzymes, participates in the metabolism of many xenobiotic compounds and endogenous lipophilic substances [7]. To date, 57 CYP450 enzymes were found in human, most of which were involved in the biosynthesis of essential sterols, signaling molecules, and regulatory factors, while some potential functions remain unclear [8]. CYP1B1 (UniGene ID Hs.154654) as the only member of CYP1B gene family was first cloned from a human keratinocyte line in 1994 [9] and confirmed in regulating the metabolic activation [10]. Simultaneously, CYP1B1 protein was observed overexpressed in the livers of patients in many cancers (including lung cancer [7]), which was strongly implying that CYP1B1 may have relevance with cancers process.

The human CYP1B1 gene is located on chromosome 2p2221 spanning approximately 12 kilobases $(\mathrm{kb})$ of DNA and is composed of three exons and two introns [11]. To our knowledge, 6 CYP1B1 SNPs had been discovered and 4 of them could lead to amino acid substitution [12]. Further, CYP1B1 SNPs have been concerned with the occurrence of various types of cancer [13-19], including lung, breast, endometrium, prostate, bladder, liver, cervix, and colorectum. Among all of the CYP1B1 SNPs, the best studied were C432G (Leu 432 Val, rs1056836) and A453G (Asn453Ser, rs1800440) on exon 3 [20]. In the current research, we analyzed genotypes of G119T 


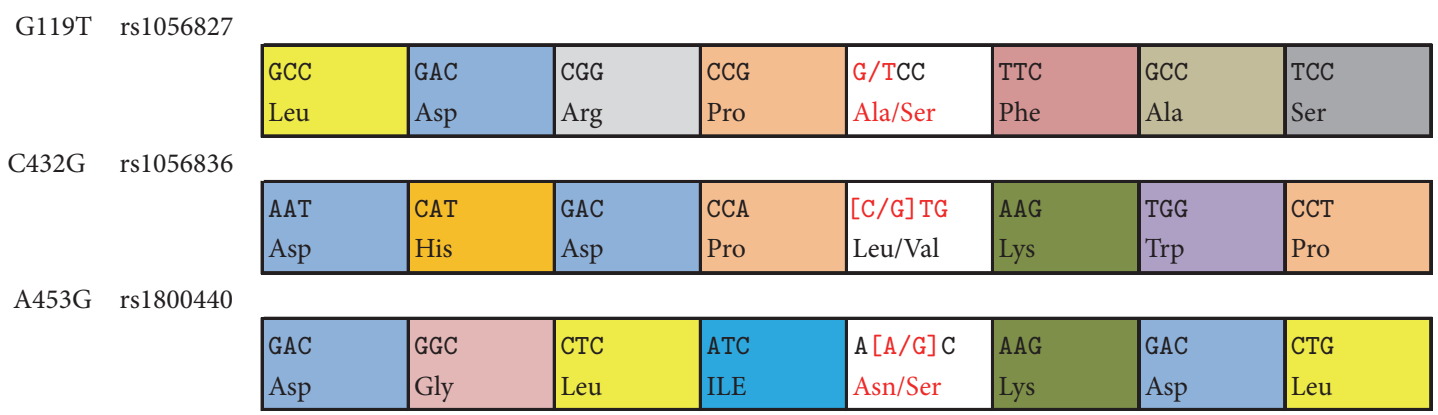

Figure 1: Mode chart of CYP1B1 G199T, C432G, and A453G SNPs.

TABLE 1: Primers design and product length for PCR-SSP.

\begin{tabular}{|c|c|c|}
\hline & & $\begin{array}{c}\text { Product } \\
\text { length }\end{array}$ \\
\hline \multicolumn{3}{|c|}{ C432G } \\
\hline Upstream & 5'-ATGCGCTTCTCCAGCTTTGT-3' & \multirow{3}{*}{$175 \mathrm{bp}$} \\
\hline Downstream 1 & $5^{\prime}$-TCCGGGTTAGGCCACTTCAG-3' & \\
\hline \multirow[t]{2}{*}{ Downstream 2} & $5^{\prime}$-TCCGGGTTAGGCCACTTCAC-3' & \\
\hline & G119T & \multirow{4}{*}{$347 \mathrm{bp}$} \\
\hline Upstream & 5'-ATGCGCTTCTCCAGCTTTGT-3' & \\
\hline Downstream 1 & $\begin{array}{c}5^{\prime} \text {-TCTGCTGGTCAGGTC-CTTGT- } \\
3^{\prime}\end{array}$ & \\
\hline \multirow[t]{2}{*}{ Downstream 2} & $5^{\prime}$-TCTGCTGGTCAGGTCCTTGC-3' & \\
\hline & A453G & \\
\hline Upstream & 5'-ATGCGCTTCTCCAGCTTTGT-3' & \\
\hline Downstream 1 & $5^{\prime}$-TCTGCAGGTCCTGGTCTTGC-3' & $328 \mathrm{bp}$ \\
\hline Downstream 2 & 5'-TCTGCAGGTCTGGTCCTTGT-3' & \\
\hline
\end{tabular}

(Alal19Ser, rs1056827) codon on exon 2 and C432G (Leu 432 Val) and A453G (Asn453Ser) on exon 3 [13], to explore the relevance between CYP1B1 genetic SNPs and postoperative prognosis of NSCLC patients.

\section{Material and Methods}

2.1. Study Population. A total of 164 consecutive NSCLC patients treated by Video-Assisted Thoracoscopic Surgery (VATS) in the Department of Thoracic Surgery, the 1st Hospital of Dalian Medical University, Liaoning Province, China, during June 2011 to June 2012 were enrolled in the study. Baseline data such as gender, age, and smoking history were recorded by the initial questionnaire. All of those patients accepted conventional three-port VATS lobectomy by the same surgeon and had completed postoperative pathological reports showing the pathological types, pTNM stages, clinical stages, and the degrees of tumor differentiation. Prognostic data such as recurrence and survival status was recorded by regular postoperative rechecks and calling back interview, and the end point of the follow-up was 61 months after the first operation (48 months after the last operation). The TNM stages and clinical stages were defined according to the Eighth Edition of the IASLC TNM Classification for Lung Cancer
[21-23]. Those patients who reportedly had previous cancer, other metastasized tumors, and preoperative radiotherapy or chemotherapy were excluded. This research was also approved by the local ethics committee, and the informed consent form according to the Declaration of Helsinki was obtained by each subject.

2.2. DNA Isolation and Genotyping Assays. Mode chart [24] of CYP1B1 G199T, C432G, and A453G SNPs was shown in Figure 1. Peripheral venous blood samples $(2 \mathrm{~mL})$ from each patient were collected before surgery in EDTA tubes and were quickly put into the liquid nitrogen tank. Then the samples were transferred into the lab and were stored in $-80^{\circ} \mathrm{C}$ for DNA isolation. Genomic DNA was extracted from the blood samples by using the TaKaRa Blood Genome DNA Extraction $\mathrm{Kit}$, and extraction process was referred to the recommended protocol. SNP genotyping was performed using polymerase chain reaction-sequence specific primer technique (PCRSSP). Primers and product length were designed according to previous literature (Table 1) [12]. The PCRs were performed on $94^{\circ} \mathrm{C}$ for $3 \mathrm{~min}$ to degeneration, followed by 30 cycles of $94^{\circ} \mathrm{C}$ for $30 \mathrm{~s}, 56^{\circ} \mathrm{C}$ for $30 \mathrm{~s}$, and $72^{\circ} \mathrm{C}$ for $30 \mathrm{~s}$, and a final extension at $72^{\circ} \mathrm{C}$ for $5 \mathrm{~min}$. The extended chains were cut by BsrI and MwoIs restriction enzyme. Genotype of each subject was finally detected by FluorChem FC2 UV transmission imaging system. Each SNP found was tested for deviation from Hardy-Weinberg equilibrium using SNPstats and Haploview $[25,26]$.

2.3. Statistical Analysis. Statistical data was analyzed using IBM Statistical Product and Service Solutions 22.0 (SPSS 22.0). Differences of clinical characteristics across genotypes were evaluated using Chi-square test and Fisher exact probability test. In those variables existing intergroup differences, Fragmentation Independence was performed by Bonferroni method to compare column proportions. To compromise the heterogeneity of the follow-up periods, survival curves were plotted with Kaplan-Meier survival analysis [27], and the differences between those curves were analyzed by the LogRank Test [28]. The Cox's proportional hazards model was applied to analyze the significance and independence of the influence of all the studied clinical and pathological factors on both tumor recurrence and cancer death risks during the follow-up period [29]. As dummy variables were established 
TABLE 2: Differences of clinical characteristics across genotypes.

\begin{tabular}{|c|c|c|c|c|c|c|c|c|c|}
\hline \multirow{2}{*}{ Clinical factors } & \multirow{2}{*}{ Total (\%) } & \multicolumn{4}{|c|}{ G119T } & \multicolumn{4}{|c|}{ C432G } \\
\hline & & $\mathrm{G} / \mathrm{G}$ & $\mathrm{G} / \mathrm{T} \& \mathrm{~T} / \mathrm{T}$ & $x^{2}$ & $p$ & $\mathrm{C} / \mathrm{C}$ & $\mathrm{C} / \mathrm{C} \& \mathrm{G} / \mathrm{G}$ & $x^{2}$ & $p$ \\
\hline Age & & & & 0.461 & $0.302_{\mathrm{f}}$ & & & 1.174 & $0.184_{f}$ \\
\hline$\geq 66$ & $86(52)$ & 53 & 33 & & & 68 & 18 & & \\
\hline Gender & & & & 1.050 & $0.297_{\mathrm{f}}$ & & & 0.269 & $0.368_{f}$ \\
\hline Male & $100(61)$ & 56 & 44 & & & 77 & 23 & & \\
\hline Tobacco use & & & & 0.041 & $0.483_{\mathrm{f}}$ & & & 0.016 & $0.526_{f}$ \\
\hline Ever & $67(41)$ & 39 & 28 & & & 51 & 16 & & \\
\hline Pathological type & & & & 1.783 & 0.619 & & & 6.476 & 0.091 \\
\hline $\mathrm{AD}$ & $78(48)$ & 44 & 34 & & & 52 & 26 & & \\
\hline SQ & $56(34)$ & 37 & 19 & & & 47 & 9 & & \\
\hline LA & $19(12)$ & 10 & 9 & & & 16 & 3 & & \\
\hline Others & $11(7)$ & 6 & 5 & & & 9 & 2 & & \\
\hline Differentiation & & & & 11.176 & 0.004 & & & 0.970 & 0.616 \\
\hline Well & $50(30)$ & $20_{\mathrm{a}}$ & $30_{a}$ & & & 39 & 11 & & \\
\hline Moderate & $89(57)$ & $599_{b}$ & $30_{b}$ & & & 68 & 21 & & \\
\hline Poor & $25(15)$ & $18_{\mathrm{b}}$ & $7_{\mathrm{b}}$ & & & 17 & 8 & & \\
\hline \multicolumn{10}{|l|}{ pTNM } \\
\hline $\mathrm{T}$ & & & & 9.448 & 0.024 & & & 5.657 & 0.130 \\
\hline $\mathrm{T} 1$ & $36(22)$ & $27 \mathrm{a}$ & $9_{\mathrm{a}}$ & & & 30 & 6 & & \\
\hline $\mathrm{T} 2$ & $60(37)$ & $36_{a, b}$ & $24_{\mathrm{a}, \mathrm{b}}$ & & & 49 & 11 & & \\
\hline $\mathrm{T} 3$ & $45(27)$ & $26_{a, b}$ & $19_{\mathrm{a}, \mathrm{b}}$ & & & 30 & 15 & & \\
\hline $\mathrm{T} 4$ & $23(14)$ & $8_{\mathrm{b}}$ & $15_{\mathrm{b}}$ & & & 15 & 8 & & \\
\hline $\mathrm{N}$ & & & & 1.287 & 0.732 & & & 1.320 & 0.724 \\
\hline No & $81(49)$ & 45 & 29 & & & 55 & 19 & & \\
\hline N1 & $31(19)$ & 8 & 15 & & & 24 & 9 & & \\
\hline $\mathrm{N} 2$ & $49(30)$ & 33 & 21 & & & 42 & 12 & & \\
\hline N3 & $3(2)$ & 1 & 2 & & & 3 & 0 & & \\
\hline $\mathrm{M}$ & & & & 0.076 & $0.477_{f}$ & & & 0.102 & $0.490_{\mathrm{f}}$ \\
\hline M0 & $141(86)$ & 84 & 57 & & & 106 & 35 & & \\
\hline M1 & $23(14)$ & 13 & 10 & & & 18 & 5 & & \\
\hline Clinical stages & & & & 5.206 & 0.267 & & & 1.232 & 0.873 \\
\hline I & $51(31)$ & 32 & 19 & & & 36 & 15 & & \\
\hline II & $16(10)$ & 9 & 7 & & & 13 & 3 & & \\
\hline IIIa & $59(36)$ & 38 & 21 & & & 45 & 14 & & \\
\hline IIIb & $15(9)$ & 5 & 10 & & & 12 & 3 & & \\
\hline IV & $23(14)$ & 13 & 10 & & & 18 & 5 & & \\
\hline
\end{tabular}

$\overline{\mathrm{a}, \mathrm{b}}$ Each subscript letter denotes a subset of the variate categories whose column proportions do not differ significantly from each other at the 0.05 level, as were calculated by Bonferroni method.

${ }^{\mathrm{f}}$ The $p$ value was adjusted by Fisher's exact probability.

$\mathrm{AD}$, adenocarcinoma; $\mathrm{SQ}$, squamous carcinoma; LA, large cell carcinoma; $\mathrm{T}$, tumor staging; $\mathrm{N}$, lymph node staging; $\mathrm{M}$, metastasis staging.

to analyze polytomous variables, the method of variables entering the Cox's equation was limited to the 'Enter' method, which means all the variables entered the equation at the same time. The difference was considered to be significant at $p<0.05$.

\section{Results}

3.1. Differences of Pathological and Clinical Factors across Genotypes. Differences of clinical characteristics across genotypes were shown in Table 2. 100 (61\%) male and 64 (39\%) female NSCLC patients were included in the study. The mean age was $64.4 \pm 11.5$ (median $=66$, ranging from 26 to 83). Genotype frequencies were shown in Table 2. In the total of 164 subjects, we detected three genotypes for G119T codon, including the wild type $(\mathrm{G} / \mathrm{G})$ in 97 patients and two mutant types (G/T and T/T) in 60 and 7 patients, respectively. For $\mathrm{C} 432 \mathrm{G}$ codon, we also detected three genotypes, including the wild type $(\mathrm{C} / \mathrm{C})$ in 124 patients and two mutant types (C/G and $\mathrm{G} / \mathrm{G})$ in 35 and 5 patients, 
TABLE 3: Cox's proportional hazard regression model for univariate analysis.

\begin{tabular}{|c|c|c|c|c|c|c|c|c|}
\hline \multirow{3}{*}{ Variables } & \multicolumn{4}{|c|}{ Disease-free survival } & \multicolumn{4}{|c|}{ Overall survival } \\
\hline & \multirow{2}{*}{$p$} & \multirow{2}{*}{$\operatorname{Exp}(\mathrm{B}) / \mathrm{HR}$} & \multicolumn{2}{|c|}{$95 \% \mathrm{CI}$} & \multirow{2}{*}{$p$} & \multirow{2}{*}{$\operatorname{Exp}(\mathrm{B}) / \mathrm{HR}$} & \multicolumn{2}{|c|}{$95 \% \mathrm{CI}$} \\
\hline & & & Lower & Upper & & & Lower & Upper \\
\hline Gender (male) & 0.119 & 1.425 & 0.913 & 2.224 & 0.165 & 1.377 & 0.876 & 2.162 \\
\hline Age $(\geq 66)$ & 0.710 & 0.924 & 0.608 & 1.404 & 0.648 & 0.906 & 0.593 & 1.383 \\
\hline Smoking (never) & 0.807 & 1.054 & 0.690 & 1.610 & 0.777 & 1.064 & 0.694 & 1.630 \\
\hline \multicolumn{9}{|l|}{ Pathological type } \\
\hline $\mathrm{AD}$ & 0.017 & 1.000 & & & 0.019 & 1.000 & & \\
\hline SQ & 0.164 & 0.707 & 0.433 & 1.153 & 0.266 & 0.754 & 0.459 & 1.240 \\
\hline LA & 0.040 & 1.877 & 1.028 & 3.428 & 0.024 & 2.005 & 1.096 & 3.669 \\
\hline Others & 0.209 & 0.519 & 0.187 & 1.444 & 0.269 & 0.561 & 0.202 & 1.564 \\
\hline \multicolumn{9}{|l|}{ Differentiation } \\
\hline Poor & 0.012 & 1.000 & & & 0.004 & 1.000 & & \\
\hline Moderate & 0.119 & 0.701 & 0.449 & 1.096 & 0.124 & 0.704 & 0.451 & 1.101 \\
\hline Well & 0.004 & 0.298 & 0.131 & 0.675 & 0.001 & 0.212 & 0.082 & 0.543 \\
\hline \multicolumn{9}{|l|}{ T stage } \\
\hline $\mathrm{T} 1$ & 0.001 & 1.000 & & & 0.001 & 1.000 & & \\
\hline $\mathrm{T} 2$ & 0.002 & 3.265 & 1.571 & 6.788 & 0.000 & 0.187 & 0.083 & 0.422 \\
\hline $\mathrm{T} 3$ & 0.008 & 2.773 & 1.298 & 5.924 & 0.076 & 0.590 & 0.329 & 1.057 \\
\hline $\mathrm{T} 4$ & 0.000 & 5.196 & 2.305 & 11.713 & 0.082 & 0.580 & 0.315 & 1.071 \\
\hline \multicolumn{9}{|l|}{$\mathrm{N}$ stage } \\
\hline N0 & 0.000 & 1.000 & & & 0.000 & 1.000 & & \\
\hline N1 & 0.017 & 2.073 & 1.140 & 3.768 & 0.004 & 2.447 & 1.331 & 4.499 \\
\hline $\mathrm{N} 2$ & 0.000 & 3.197 & 1.938 & 5.276 & 0.000 & 3.589 & 2.146 & 6.002 \\
\hline N3 & 0.002 & 7.186 & 2.117 & 24.396 & 0.001 & 7.839 & 2.318 & 26.516 \\
\hline M stage (M1) & 0.000 & 2.538 & 1.526 & 4.221 & 0.001 & 2.484 & 1.478 & 4.174 \\
\hline \multicolumn{9}{|l|}{ Clinical stage } \\
\hline I & 0.000 & 1.000 & & & 0.000 & 1.000 & & \\
\hline II & 0.003 & 3.513 & 1.538 & 8.025 & 0.001 & 3.923 & 1.693 & 9.092 \\
\hline IIIa & 0.001 & 2.844 & 1.500 & 5.394 & 0.001 & 3.194 & 1.653 & 6.173 \\
\hline IIIb & 0.000 & 5.266 & 2.348 & 11.810 & 0.000 & 5.608 & 2.466 & 12.751 \\
\hline $\mathrm{V}$ & 0.000 & 5.896 & 2.899 & 11.989 & 0.000 & 6.246 & 3.002 & 12.997 \\
\hline G199T (mutant) & 0.030 & 1.592 & 1.047 & 2.420 & 0.022 & 1.640 & 1.074 & 2.505 \\
\hline C432G (mutant) & 0.700 & 0.905 & 0.545 & 1.504 & 0.603 & 0.874 & 0.525 & 1.454 \\
\hline
\end{tabular}

respectively. However, we could only detect the A/A genotype for $\mathrm{A} 453 \mathrm{G}$ codon in most subjects, while $\mathrm{A} / \mathrm{G}$, a rare variant of CYP1B1 gene A453G codon, was found in 2 patients. For A453G codon, G/G variant was not found in the study population. These findings implied that there might not exist statistically significant SNP of CYP1B1 gene A453G codon in the Chinese population. When assessing each SNP, patients were divided into two groups by wild or mutant genotypes. Chi-square test and Fisher exact probability test were used to evaluate intergroup difference. Among all the included clinical and pathological factors, only the degree of tumor differentiation $\left(\chi^{2}=11.176, p=0.004\right)$ and pathological $\mathrm{T}$ stage $\left(\chi^{2}=9.448, p=0.024\right)$ caused significant difference across G199T genotypes. None of the variables showed intergroup difference across C432G genotypes.

3.2. Survival Analysis. Within the complete follow-up period, 88 patients $(53.7 \%)$ had recurrences (mean $=9$ months, ranging from 0 to 53 months). 86 patients (52.4\%) in those who had recurrence were killed. Three patients were killed by other reasons. Kaplan-Meier survival analysis was used to describe the survival curves of both overall and disease-free survival status (Figure 2). We found that patients with G119T wild type $(\mathrm{G} / \mathrm{G})$ had benefits in both disease-free $(p=0.26)$ and overall $(p=0.19)$ survival time compared with those carrying mutant types (G/T or T/T). However, there was no significant difference in overall nor disease-free survival time between patients with $\mathrm{C} 432 \mathrm{G}$ wild type $(\mathrm{C} / \mathrm{C})$ and mutant types $(\mathrm{C} / \mathrm{G}$ or $\mathrm{G} / \mathrm{G}, p<0.05)$. Besides, a Cox's proportional hazard regression model was performed. Univariate analysis (Table 3) showed that, along with pathological types, tumor differentiation, pTNM stages, and clinical stages, G199T polymorphism was an influence factor of both recurrence $(\mathrm{HR}=1.592,95 \%$ CI 1.047-2.420, $p=0.03)$ and cancer death $(\mathrm{HR}=1.640,95 \%$ CI 1.074-2.505, $p=0.022)$ risks, while $\mathrm{C} 432 \mathrm{G}$ genotype was not. Further, in multivariate analysis 


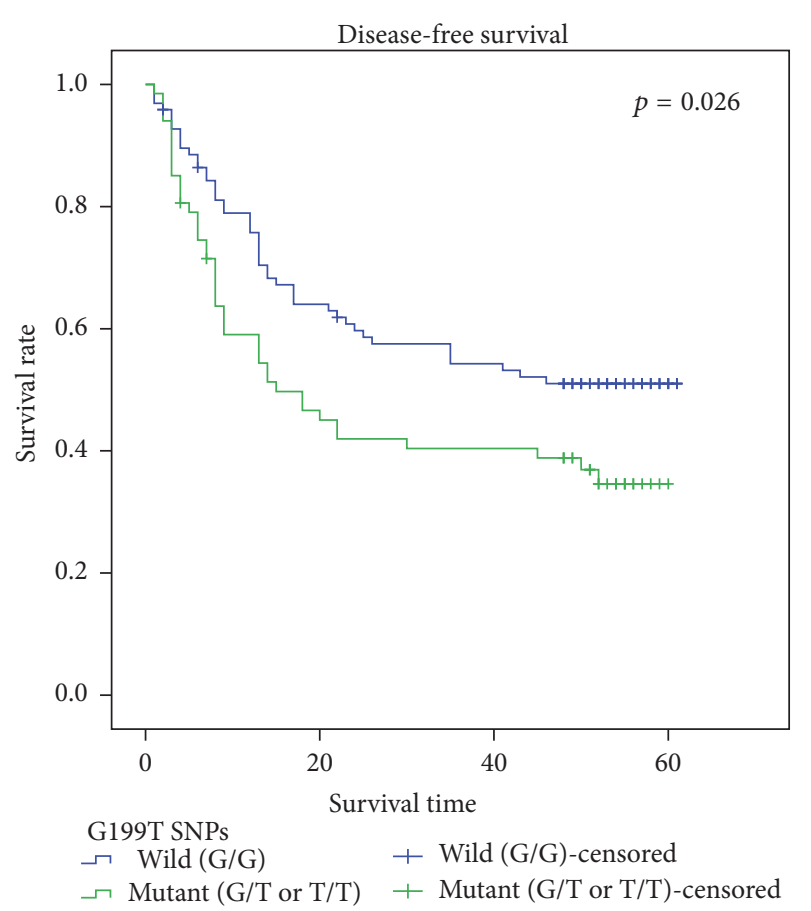

(a)

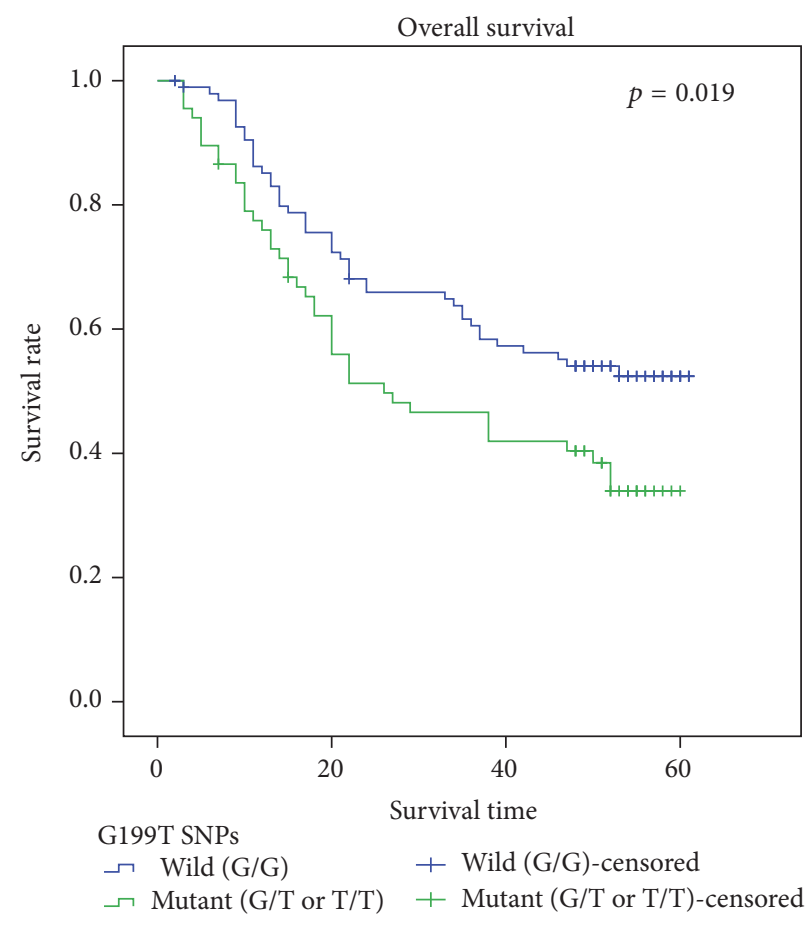

(c)



(b)

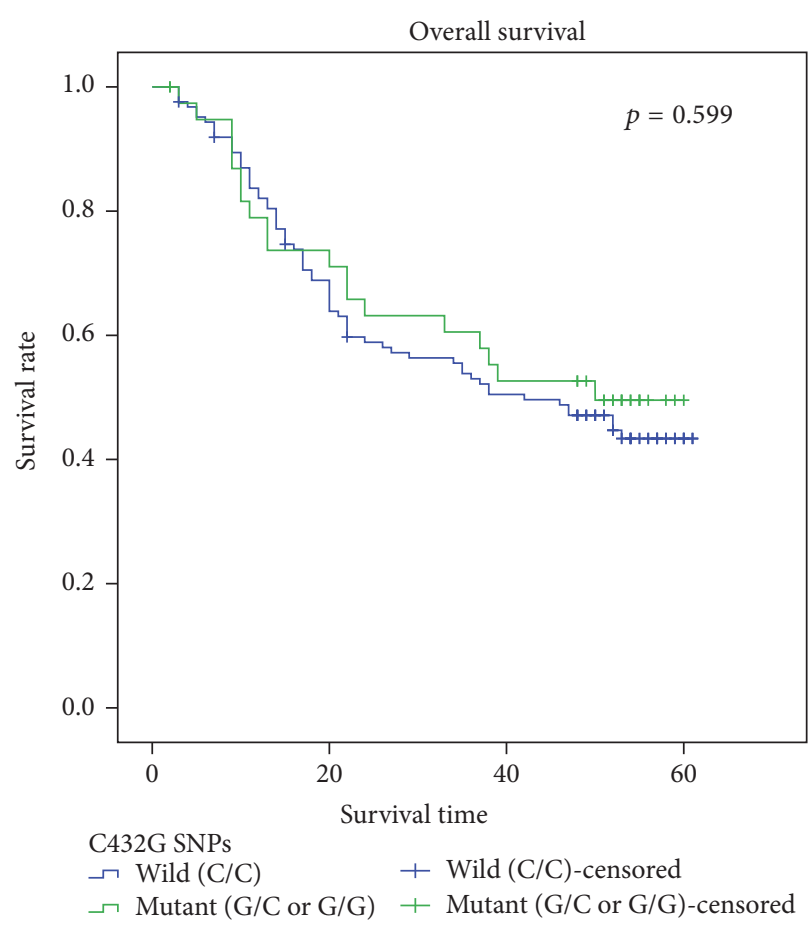

(d)

FIGURE 2: Kaplan-Meier survival analysis for disease-free and overall survival time. 
TABLE 4: Cox's proportional hazard regression model for multivariate analysis.

\begin{tabular}{|c|c|c|c|c|c|c|c|c|}
\hline \multirow{3}{*}{ Variables } & \multicolumn{4}{|c|}{ Disease-free survival } & \multicolumn{4}{|c|}{ Overall survival } \\
\hline & \multirow{2}{*}{$p$} & \multirow{2}{*}{$\operatorname{Exp}(\mathrm{B}) / \mathrm{HR}$} & \multicolumn{2}{|c|}{$95 \% \mathrm{CI}$} & \multirow{2}{*}{$p$} & \multirow{2}{*}{$\operatorname{Exp}(\mathrm{B}) / \mathrm{HR}$} & \multicolumn{2}{|c|}{$95 \% \mathrm{CI}$} \\
\hline & & & Lower & Upper & & & Lower & Upper \\
\hline Gender (male) & 0.088 & 1.679 & 0.926 & 3.045 & 0.265 & 1.400 & 0.775 & 2.529 \\
\hline Age $(\geq 66)$ & 0.180 & 1.412 & 0.852 & 2.339 & 0.102 & 1.539 & 0.918 & 2.580 \\
\hline Smoking (never) & 0.088 & 0.623 & 0.362 & 1.074 & 0.082 & 0.608 & 0.347 & 1.064 \\
\hline \multicolumn{9}{|l|}{ Pathological type } \\
\hline $\mathrm{AD}$ & 0.014 & 1.000 & & & 0.001 & 1.000 & & \\
\hline SQ & 0.137 & 0.624 & 0.335 & 1.162 & 0.230 & 0.674 & 0.354 & 1.284 \\
\hline LA & 0.050 & 2.018 & 0.999 & 4.078 & 0.005 & 2.834 & 1.371 & 5.859 \\
\hline Others & 0.642 & 0.775 & 0.264 & 2.273 & 0.871 & 1.096 & 0.363 & 3.306 \\
\hline \multicolumn{9}{|l|}{ Differentiation } \\
\hline Poor & 0.139 & 1.000 & & & 0.028 & 1.000 & & \\
\hline Moderate & 0.256 & 0.753 & 0.462 & 1.228 & 0.155 & 0.700 & 0.428 & 1.144 \\
\hline Well & 0.055 & 0.412 & 0.167 & 1.018 & 0.009 & 0.255 & 0.091 & 0.712 \\
\hline \multicolumn{9}{|l|}{ T stage } \\
\hline $\mathrm{T} 1$ & 0.002 & 1.000 & & & 0.001 & 1.000 & & \\
\hline $\mathrm{T} 2$ & 0.000 & 4.051 & 1.858 & 8.835 & 0.000 & 4.320 & 1.978 & 9.435 \\
\hline $\mathrm{T} 3$ & 0.040 & 2.422 & 1.040 & 5.640 & 0.007 & 3.171 & 1.379 & 7.290 \\
\hline $\mathrm{T} 4$ & 0.003 & 5.524 & 1.783 & 17.109 & 0.001 & 7.859 & 2.425 & 25.467 \\
\hline \multicolumn{9}{|l|}{$\mathrm{N}$ stage } \\
\hline N0 & 0.161 & 1.000 & & & 0.031 & 1.000 & & \\
\hline N1 & 0.572 & 0.763 & 0.299 & 1.948 & 0.932 & 1.043 & 0.398 & 2.734 \\
\hline N2 & 0.170 & 1.659 & 0.805 & 3.418 & 0.014 & 2.613 & 1.212 & 5.630 \\
\hline N3 & 0.313 & 2.236 & 0.469 & 10.667 & 0.215 & 2.681 & 0.565 & 12.719 \\
\hline M stage (M1) & 0.001 & 5.499 & 2.079 & 14.543 & 0.002 & 4.708 & 1.746 & 12.689 \\
\hline \multicolumn{9}{|l|}{ Clinical stage $_{\mathrm{a}}$} \\
\hline I & 0.049 & 1.000 & & & 0.115 & 1.000 & & \\
\hline II & 0.005 & 6.274 & 1.725 & 22.816 & 0.018 & 4.878 & 1.316 & 18.076 \\
\hline IIIa & 0.089 & 2.312 & 0.881 & 6.064 & 0.302 & 1.701 & 0.621 & 4.658 \\
\hline IIIb & 0.219 & 2.413 & 0.593 & 9.824 & 0.522 & 1.595 & 0.383 & 6.647 \\
\hline G199T (mutant) & 0.491 & 1.176 & 0.742 & 1.863 & 0.478 & 1.185 & 0.741 & 1.896 \\
\hline C432G (mutant) & 0.536 & 1.200 & 0.674 & 2.138 & 0.665 & 1.137 & 0.637 & 2.30 \\
\hline
\end{tabular}

${ }^{\mathrm{a}}$ Constant or linearly dependent covariates clinical stage $\mathrm{V}=\mathrm{M}$ stage 1 .

(Table 4), we found that pathological types, clinical staging, and pTMN staging were still significant influence factors of NSCLC long-term risks, but neither G119T nor C432G genotype could be an independent predictor for prognosis.

\section{Discussion}

During the last 30 years, the diagnosis and treatment of lung cancer had undergone great improvement; however the prognosis remained optimistic [30]. Even for stage I NSCLC patients, approximately $30 \%$ of patients would have recurrences of the tumor and die despite complete surgical resection [31]. The prognosis of lung cancer is associated with multiple factors, such as surgery technology, perioperative management, degree of tumor differentiation, pTNM stage, clinical stage, and postoperative therapies [32]. Besides, there have been numerous studies on genetic SNPs as the predictors of prognosis in patients with NSCLC after surgical resection.
For example, in 2015, Lee [33] and colleagues identified 8 human SNPs significantly associated with NSCLC prognosis, including CD3EAP rs967591, TNFRSF10B rs1047266, AKT1 rs3803300, C3 rs2287845, HOMER2 rs1256428, GNB2L1 rs3756585, ADAMTSL3 rs11259927, and CD3D rs3181259. Chen [34] and colleagues reported VEGF rs3025039 polymorphism could influence the response to chemotherapy and overall survival of NSCLC patients. Most SNPs, which were found to affect NSCLC prognosis, belonged to genes encoding important proteins in the cancer process.

The occurring and development of cancer are associated with abnormity of multiple cancer-related genes, among which CYP1B1 acts as an important phase I metabolism enzyme participating in regulating the metabolic activation [35]. Over the last two decades, a number of case-control studies were conducted to investigate the association between CYP1B1 gene polymorphism and cancer risk in humans [1319]. Researchers considered that it was the SNPs which led to 
amino acids substitution resulting in conformational variation of the CYP1B1 protein and thus causing downregulation of activity or change in function of the enzyme. This change might weaken the capability on procarcinogen metabolism of body and therefore increased susceptibility to cancer [16, 17]. Besides, numerous researches believed that the constituent ratio of CYP1B1 polymorphisms possesses regional and ethnic differences [10,36-39]. In the current study, the constituent ratio of each enrolled SNP was in accordance with previous reports about other Chinese populations (there were also some Chinese written articles in domestic journals giving similar reports) $[10,37,40]$. For CYP1B1 A453G codon, we did not find statistically significant SNPs among the study groups. This finding was in accordance with most researches enrolling A543G codon among Chinese, suggesting that there did not exist A453G SNPs in Chinese Han population.

CYP family was well known to be associated with drug metabolism [41]. Lots of CYP superfamilies such as CYP1A, CYP2C, CYP2E, CYP2D, and CYP3A [42-44] appeared to have mutual effect with numerous drugs. However, the role of CYP1B superfamily in drug metabolism was rarely studied, especially for anticancer drugs. Before us, there was no report on the influence of CYP1B1 gene polymorphisms on lung cancer prognosis. As some reports said that downregulation of P450 enzymes expression is associated with tumor progression [45], we assume that the changes of enzyme activity or function caused by CYP1B1 gene SNPs could either have immediate influence on tumor process or cause boost or block in drug metabolism which could indirectly affect tumor process and therefore affect long-term survival conditions. Among all of the 164 NSCLC cases, the study showed those patients carrying G199T mutant (G/T or T/T) genotypes suffered from higher expectation of recurrence and shorter survival time. Although the result of Cox's model multivariate analysis implied that the polymorphism of G199T could not independently affect NSCLC long-term prognosis, those patients with G199T mutant genotypes (G/T or G/G) tend to have later $\mathrm{T}$ stages and poorer tumor differentiation, which were confirmed as independent risk factors of recurrence and cancer death. This finding implied that although G199T SNP cannot act as an independent predictor for NSCLC postoperative prognosis, it could be an auxiliary predictor. It is implied that patients carrying G199T mutant genotypes might had worse clinical and pathological conditions, as well as lower expectation of disease-free and overall survival time, who perhaps need additional adjuvant therapy. However, we still know little about the exact mechanism of CYP1B1 gene SNPs interacting with tumor development. We assumed that it was also the shift in enzyme activity or function caused by base-pair substitution that affected tumor progress.

\section{Conclusion}

This study showed CYP1B1 gene G199T SNP could be useful to identify patients with a higher risk of tumor recurrence and death after surgical resection of NSCLC and thereby help to select patients for preoperative or postoperative drug adjuvant therapies. Besides CYP1B1 G199T alleles could also be a potential target for precise drug intervention, as well as a candidate for further research in the field of anticancer drugs. Studies are required to confirm the validity of this SNP in other ethnic populations, and the mechanism of CYP1B1 genetic polymorphism affecting cancer progress should be explored in vitro and in vivo.

\section{Competing Interests}

No conflict of interests exits in the submission of this manuscript.

\section{Authors' Contributions}

All authors contributed to the design of the study and the preparation and critical revision of the manuscript and agreed to be accountable for all aspects of the study. The manuscript is approved by all authors for publication. Fengzhou Li and Shaofeng Zhang contributed equally to this study.

\section{Acknowledgments}

This work was supported by grants from the National Natural Science Foundation of China (81173453), Natural Science Foundation of Liaoning Province, China (201602227), and Municipal Science and Technology Program of Dalian, China (2012E15SF141).

\section{References}

[1] W. Chen, R. Zheng, P. D. Baade et al., "Cancer statistics in China, 2015," CA: A Cancer Journal for Clinicians, vol. 66, no. 2, pp. 115132,2016

[2] D. E. Ost, S.-C. J. Yeung, L. T. Tanoue, and M. K. Gould, "Clinical and organizational factors in the initial evaluation of patients with lung cancer: diagnosis and management of lung cancer, 3rd ed: American college of chest physicians evidence-based clinical practice guidelines," Chest, vol. 143, no. 5, pp. el21-e141, 2013.

[3] D. S. Ettinger, "Ten years of progress in non-small cell lung cancer," JNCCN Journal of the National Comprehensive Cancer Network, vol. 10, no. 3, pp. 292-295, 2012.

[4] L. A. G. Ries, M. E. Reichman, D. R. Lewis, B. F. Hankey, and B. K. Edwards, "Cancer survival and incidence from the surveillance, epidemiology, and end Results (SEER) program," Oncologist, vol. 8, no. 6, pp. 541-552, 2003.

[5] A. N. Orekhov, "Evidence based efficacy of herbal preparations in ageing associated cardiovascular disorders," Phytomedicine, vol. 23, no. 11, pp. 1065-1067, 2016.

[6] I. A. Sobenin and A. N. Orekhov, "Mechanistic biomarkers: the field for the development of non-pharmaceutical and pharmaceutical approaches to diagnostics, prevention and treatment of chronic diseases," Current Pharmaceutical Design, vol. 22, no. 3, pp. 265-267, 2016.

[7] P. H. Roos and H. M. Bolt, "Cytochrome P450 interactions in human cancers: new aspects considering CYP1B1," Expert Opinion on Drug Metabolism and Toxicology, vol. 1, no. 2, pp. 187-202, 2005.

[8] F. P. Guengerich, "Human cytochrome P450 enzymes," in Cytochrome P450, O. de Montellano, Ed., pp. 377-530, Kluwer/ Plenum/Elsevier, New York, NY, USA, 2005. 
[9] D. R. Nelson, L. Koymans, T. Kamataki et al., "P450 superfamily: update on new sequences, gene mapping, accession numbers and nomenclature," Pharmacogenetics, vol. 6, no. 1, pp. 1-42, 1996.

[10] J. Watanabe, T. Shimada, E. M. J. Gillam et al., "Association of CYP1B1 genetic polymorphism with incidence to breast and lung cancer," Pharmacogenetics, vol. 10, no. 1, pp. 25-33, 2000.

[11] Y. M. Tang, Y.-Y. P. Wo, J. Stewart et al., "Isolation and characterization of the human cytochrome p450 CYP1B1 gene," Journal of Biological Chemistry, vol. 271, no. 45, pp. 2832428330, 1996.

[12] G. I. Murray, W. T. Melvin, W. F. Greenlee, and M. D. Burke, "Regulation, function, and tissue-specific expression of cytochrome P450 CYP1B1," Annual Review of Pharmacology and Toxicology, vol. 41, pp. 297-316, 2001.

[13] R.-E. Go, K.-A. Hwang, and K.-C. Choi, "Cytochrome P450 1 family and cancers," Journal of Steroid Biochemistry and Molecular Biology, vol. 147, pp. 24-30, 2015.

[14] J.-Y. Liu, Y. Yang, Z.-Z. Liu, J.-J. Xie, Y.-P. Du, and W. Wang, "Association between the CYP1B1 polymorphisms and risk of cancer: a meta-analysis," Molecular Genetics and Genomics, vol. 290, no. 2, pp. 739-765, 2015.

[15] K. Gajjar, P. L. Martin-Hirsch, and F. L. Martin, "CYP1B1 and hormone-induced cancer," Cancer Letters, vol. 324, no. 1, pp. 1330, 2012.

[16] A. S. Salinas-Sánchez, M. J. Donate-Moreno, M.-P. LópezGarrido, J. M. Giménez-Bachs, and J. Escribano, "Role of CYP1B1 gene polymorphisms in bladder cancer susceptibility," Journal of Urology, vol. 187, no. 2, pp. 700-706, 2012.

[17] F. Liu, L.-M. Luo, Y.-G. Wei et al., "Polymorphisms of the CYP1B1 gene and hepatocellular carcinoma risk in a Chinese population," Gene, vol. 564, no. 1, pp. 14-20, 2015.

[18] Y. Xie, G.-Q. Liu, X.-Y. Miao, Y. Liu, W. Zhou, and D.-W. Zhong, "CYP1B1 Leu432Val polymorphism and colorectal cancer risk among Caucasians: a meta-analysis," Tumor Biology, vol. 33, no. 3, pp. 809-816, 2012.

[19] Y. Li, S.-Q. Tan, Q.-H. Ma et al., "CYP1B1 C4326G polymorphism and susceptibility to cervical cancer in Chinese Han women," Tumor Biology, vol. 34, no. 6, pp. 3561-3567, 2013.

[20] S. Bandiera, S. Weidlich, V. Harth, P. Broede, Y. Ko, and T. Friedberg, "Proteasomal degradation of human CYP1B1: effect of the Asn453Ser polymorphism on the post-translational regulation of CYP1B1 expression," Molecular Pharmacology, vol. 67, no. 2, pp. 435-443, 2005.

[21] R. Rami-Porta, V. Bolejack, J. Crowley et al., "The IASLC lung cancer staging project: proposals for the revisions of the $\mathrm{T}$ descriptors in the forthcoming eighth edition of the TNM classification for lung cancer," Journal of Thoracic Oncology, vol. 10, no. 7, pp. 990-1003, 2015.

[22] H. Asamura, K. Chansky, J. Crowley et al., "The International association for the study of lung cancer lung cancer staging project: proposals for the Revision of the $\mathrm{N}$ descriptors in the forthcoming 8th edition of the TNM classification for lung cancer," Journal of Thoracic Oncology, vol. 10, no. 12, pp. 16751684, 2015.

[23] W. E. E. Eberhardt, A. Mitchell, J. Crowley et al., "The IASLC lung cancer staging project: proposals for the revision of the $\mathrm{M}$ descriptors in the forthcoming eighth edition of the TNM classification of lung cancer," Journal of Thoracic Oncology, vol. 10, no. 11, pp. 1515-1522, 2015.
[24] Single nucleotide polymorphisms of CYP1B1 Gene, National Center for Biotechnology Information, U.S. National Library of Medicine, https://www.ncbi.nlm.nih.gov/snp/?term=CYP1B1.

[25] J. C. Barrett, B. Fry, J. Maller, and M. J. Daly, "Haploview: analysis and visualization of LD and haplotype maps," Bioinformatics, vol. 21, no. 2, pp. 263-265, 2005.

[26] X. Solé, E. Guinó, J. Valls, R. Iniesta, and V. Moreno, "SNPStats: a web tool for the analysis of association studies," Bioinformatics, vol. 22, no. 15, pp. 1928-1929, 2006.

[27] E. L. Kaplan and P. Meier, "Nonparametric estimation from incomplete observations," Journal of the American Statistical Association, vol. 53, no. 282, pp. 457-481, 1958.

[28] R. Peto, M. C. Pike, and P. Armitage, "Design and analysis of randomized clinical trials requiring prolonged observation of each patient. II. analysis and examples," British Journal of Cancer, vol. 35, no. 1, pp. 1-39, 1977.

[29] D. R. Cox, "Regression models and life-tables," Journal of the Royal Statistical Society. Series B. Methodological, vol. 34, pp. 187-220, 1972.

[30] R. Siegel, C. Desantis, K. Virgo et al., "Cancer treatment and survivorship statistics, 2012," CA Cancer Journal for Clinicians, vol. 62, no. 4, pp. 220-241, 2012.

[31] T. Osaki, T. Oyama, C.-D. Gu et al., "Prognostic impact of micrometastatic tumor cells in the lymph nodes and bone marrow of patients with completely resected stage I non-smallcell lung cancer," Journal of Clinical Oncology, vol. 20, no. 13, pp. 2930-2936, 2002.

[32] A. J. Ben, S. B. Ben, H. Zaibi, B. Dhahri, M. A. Baccar, and S. Azzabi, "Prognostic factors of advanced stage non-small-cell lung cancer," La Tunisie Médicale, vol. 94, no. 5, pp. 360-367, 2016.

[33] S. Y. Lee, J. E. Choi, H.-S. Jeon et al., "A panel of genetic polymorphism for the prediction of prognosis in patients with early stage non-small cell lung cancer after surgical resection," PLoS ONE, vol. 10, no. 10, Article ID e0140216, 2015.

[34] N. Chen, C. N. Ma, M. Zhao, and Y. J. Zhang, "Role of VEGF gene polymorphisms in the clinical outcome of non-small cell lung cancer," Genetics and Molecular Research, vol. 14, no. 4, pp. 16006-16011, 2015.

[35] P. R. O. De Montellano, "Cytochrome P450-activated prodrugs," Future Medicinal Chemistry, vol. 5, no. 2, pp. 213-228, 2013.

[36] P. P. Shah, A. P. Singh, M. Singh et al., "Association of functionally important polymorphisms in cytochrome P4501B1 with lung cancer," Mutation Research-Fundamental and Molecular Mechanisms of Mutagenesis, vol. 643, no. 1-2, pp. 4-10, 2008.

[37] J. Lai, D. Vesprini, W. Chu, H. Jernström, and S. A. Narod, “CYP gene polymorphisms and early menarche," Molecular Genetics and Metabolism, vol. 74, no. 4, pp. 449-457, 2001.

[38] V. Kumar, S. Singh, R. S. Ahmed, B. D. Banerjee, T. Ahmed, and S. T. Pasha, "Frequency of common CYP1B1 polymorphic variations in Delhi population of Northern India," Environmental Toxicology and Pharmacology, vol. 28, no. 3, pp. 392-396, 2009.

[39] M. Sasaki, Y. Tanaka, M. Kaneuchi, N. Sakuragi, and R. Dahiya, "Alleles of polymorphic sites that correspond to hyperactive variants of CYP1B1 protein are significantly less frequent in Japanese as compared to American and German populations," Human Mutation, vol. 21, no. 6, article 652, 2003.

[40] L. Cui, K. Dillehay, W. Chen, D. Shen, Z. Dong, and W. Li, "Association of the CYP1B1 Leu432Val polymorphism with the risk of prostate cancer: a meta-analysis," Molecular Biology Reports, vol. 39, no. 7, pp. 7465-7471, 2012. 
[41] R. W. Estabrook, "A passion for P450s (remembrances of the early history of research on cytochrome P450)," Drug Metabolism and Disposition, vol. 31, no. 12, pp. 1461-1473, 2003.

[42] R. Orlando, P. Piccoli, S. De Martin, R. Padrini, M. Floreani, and P. Palatini, "Cytochrome P450 1A2 is a major determinant of lidocaine metabolism in vivo: effects of liver function," Clinical Pharmacology and Therapeutics, vol. 75, no. 1, pp. 80-88, 2004.

[43] N. Torimoto, I. Ishii, M. Hata et al., "Direct interaction between substrates and endogenous steroids in the active site may change the activity of cytochrome P450 3A4," Biochemistry, vol. 42, no. 51, pp. 15068-15077, 2003.

[44] E. Tanaka, N. Kurata, and H. Yasuhara, "Involvement of cytochrome $\mathrm{P} 4502 \mathrm{C} 9,2 \mathrm{E} 1$ and $3 \mathrm{~A} 4$ in trimethadione $\mathrm{N}$ demethylation in human microsomes," Journal of Clinical Pharmacy and Therapeutics, vol. 28, no. 6, pp. 493-496, 2003.

[45] X. F. Liu, R. H. Shi, and H. J. Gao, "Cytochrome P450 relative gene down regulation has relevance with occurance and progress of primary hepatic carcinoma," Chinese Journal of Digestion, no. 4, pp. 274-275, 2006. 

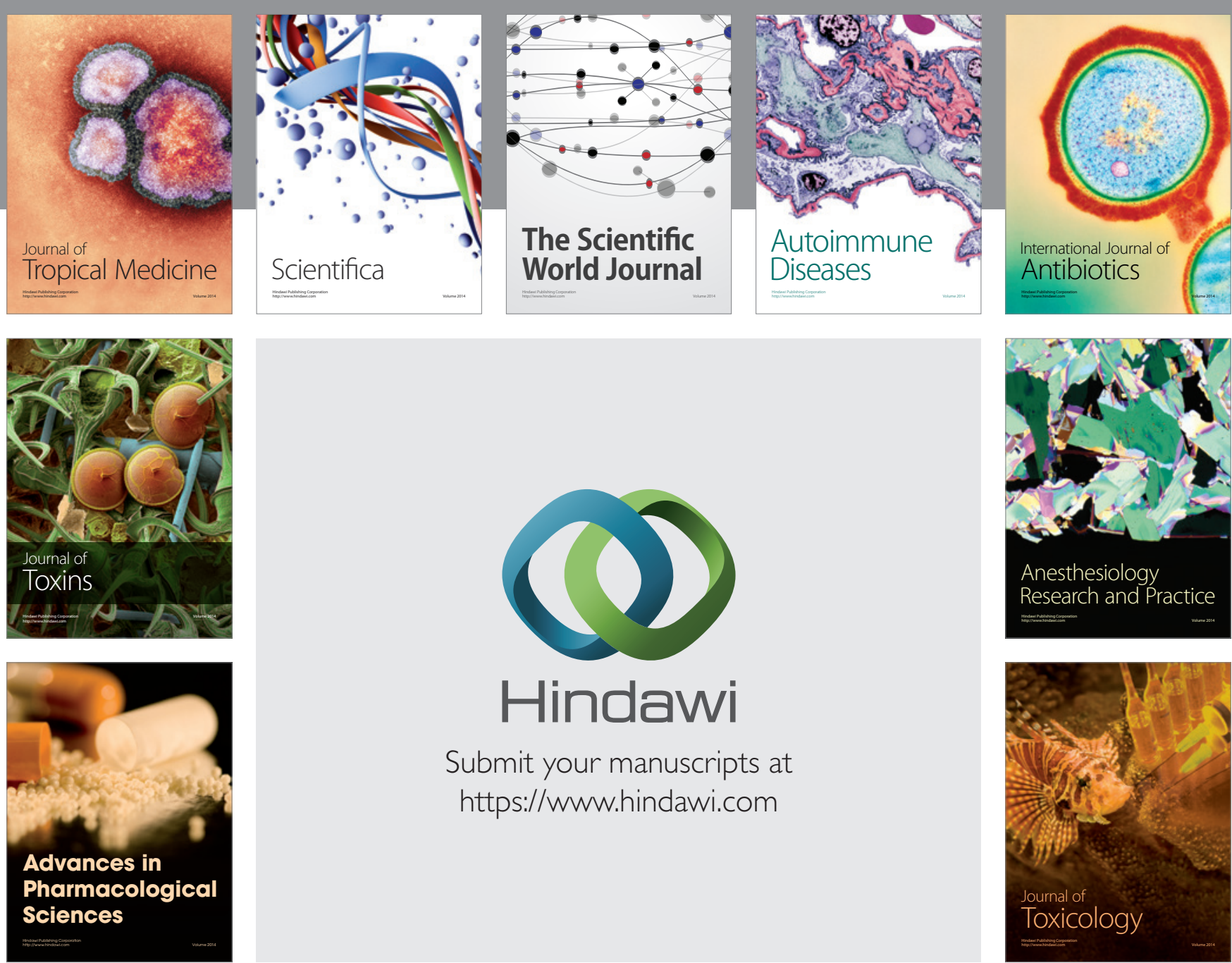

\section{Hindawi}

Submit your manuscripts at

https://www.hindawi.com
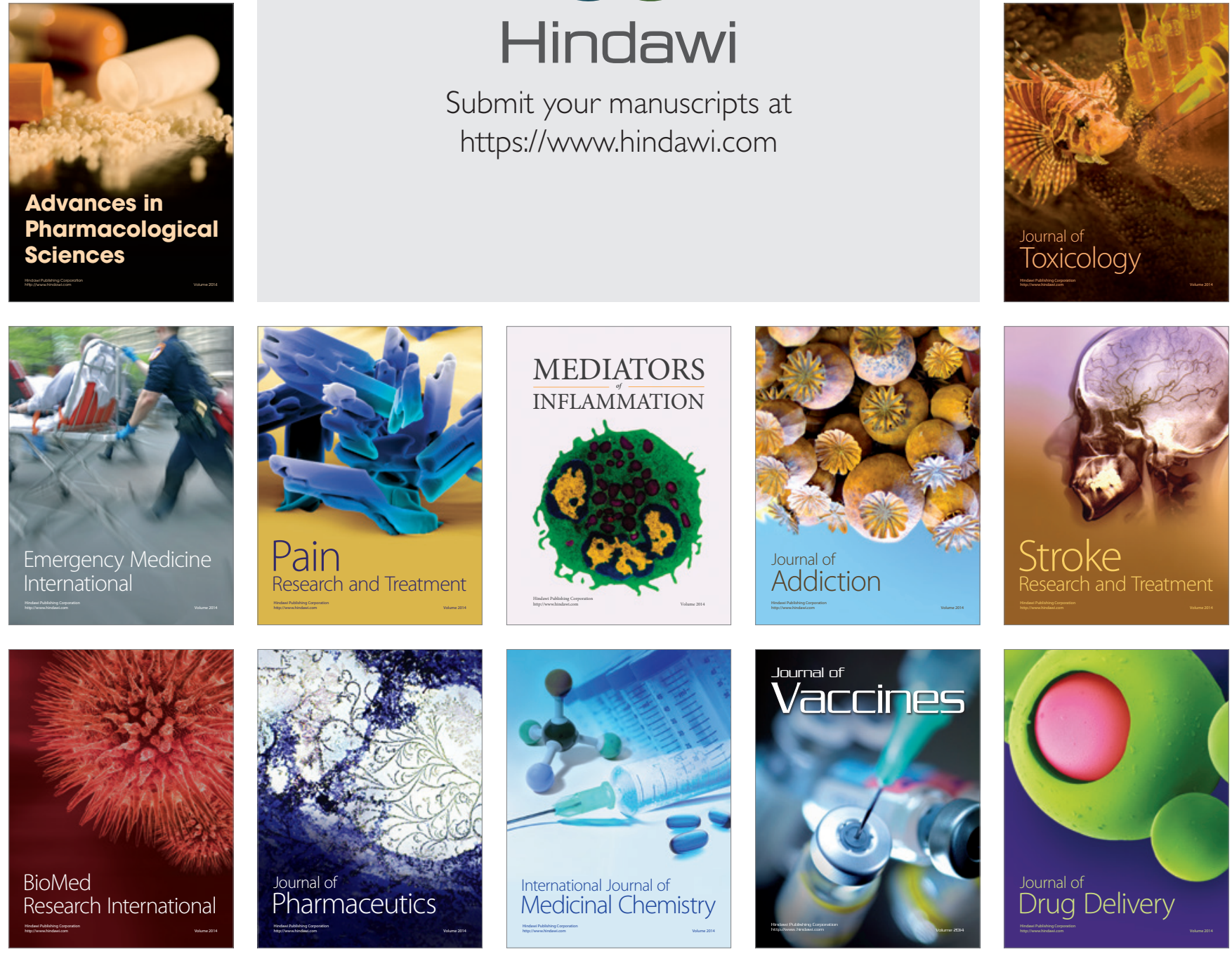